\title{
Using Accelerometry for Evaluating Energy Consumption and Running Intensity Distribution Throughout a Marathon According to Sex
}

\author{
Carlos Hernando $1,2, *\left(\mathbb{0}\right.$, Carla Hernando ${ }^{3}$, Ignacio Martinez-Navarro ${ }^{4,5}$, \\ Eladio Collado-Boira ${ }^{6}{ }^{\circ}$, Nayara Panizo ${ }^{6}$ and Barbara Hernando ${ }^{7}$ \\ 1 Sport Service, Jaume I University, 12071 Castellon, Spain \\ 2 Department of Education and Specific Didactics, Jaume I University, 12071 Castellon, Spain \\ 3 Department of Mathematics, Carlos III University of Madrid, 28911 Leganés, Madrid, Spain; \\ cahernan@math.uc3m.es \\ 4 Department of Physical Education and Sport, University of Valencia, 46010 Valencia, Spain; \\ ignacio.martinez-navarro@uv.es \\ 5 Sports Health Unit, Vithas-Nisa 9 de Octubre Hospital, 46015 Valencia, Spain \\ 6 Faculty of Health Sciences, Jaume I University, 12071 Castellon, Spain; colladoe@uji.es (E.C.-B.); \\ nayapanizo@gmail.com (N.P.) \\ 7 Department of Medicine, Jaume I University, 12071 Castellon, Spain; hernandb@uji.es \\ * Correspondence: hernando@uji.es; Tel.: +34-964-728808
}

Received: 28 July 2020; Accepted: 25 August 2020; Published: 26 August 2020

check for updates

\begin{abstract}
The proportion of females participating in long-distance races has been increasing in the last years. Although it is well-known that there are differences in how females and males face a marathon, higher research may be done to fully understand the intrinsic and extrinsic factors affecting sex differences in endurance performance. In this work, we used triaxial accelerometer devices to monitor 74 males and 14 females, aged 30 to 45 years, who finished the Valencia Marathon in 2016. Moreover, marathon split times were provided by organizers. Several physiological traits and training habits were collected from each participant. Then, we evaluated several accelerometry- and pace-estimated parameters (pacing, average change of speed, energy consumption, oxygen uptake, running intensity distribution and running economy) in female and male amateur runners. In general, our results showed that females maintained a more stable pacing and ran at less demanding intensity throughout the marathon, limiting the decay of running pace in the last part of the race. In fact, females ran at $4.5 \%$ faster pace than males in the last kilometers. Besides, their running economy was higher than males (consumed nearly 19\% less relative energy per distance) in the last section of the marathon. Our results may reflect well-known sex differences in physiology (i.e., muscle strength, fat metabolism, $\mathrm{VO}_{2 \max }$ ), and in running strategy approach (i.e., females run at a more conservative intensity level in the first part of the marathon compared to males). The use of accelerometer devices allows coaches and scientific community to constantly monitor a runner throughout the marathon, as well as during training sessions.
\end{abstract}

Keywords: accelerometry; sex; physical activity; running intensity; energy consumption; pacing; marathoners; running economy

\section{Introduction}

Marathons have growth in popularity and therefore in participants worldwide at a record pace [1-3]. However, the increase in the number of female marathoners has been delayed, as compared to male, due to different social and behavioral causes previously pointed out by Joyner and colleagues 
in 2017 [4]. Although sex ratios are still far of being equivalent (i.e., 18.7\% of females from the total number of participants in the Valencia Marathon 2019), female's participation in marathon races has increased exponentially since Kathy Swizer finished the Boston Marathon in 1967.

This situation has encouraged scientific community to study female's behavior in long-distance races and compare them with males. Studies have been focused on analyzing different factors affecting running performance such as running speed [5-8], pacing [9], physiological traits $[4,10]$, running economy $[7,11,12]$ and predominant type of metabolism used [13-15], as well as physical, biomechanical, psychological and social factors [16-19].

The assessment of physiological parameters affecting running performance has been carried out in lab-based conditions-normally by measuring the volume of expired gases (the gold standard test) $[11-13,19]$. However, lab-based conditions are far from normal race conditions. Up to now, field-based studies have been focused on estimating the energy consumption throughout a long-distance race by analyzing changes in running speed $[7,10,20-23]$. The use of portable measurement systems to obtain parameters for estimating energy consumption in real conditions is nowadays a reality [24-29].

In particular, the use of triaxial accelerometry has strongly emerged as a tool that allows the evaluation of a physical activity, in terms of duration, frequency and intensity, performed by an individual in free-living conditions [30-33]. Thus, using the cut-off points previously established for a specific population and/or an activity, the accelerometer output data allowed to indirectly estimate the energy cost of an activity [34-38].

With the aim of monitoring middle-aged recreational marathoners during a marathon using accelerometry-based devices, our research group has established the GENEActiv ${ }^{\circledR}$ cut-off points, under lab-based conditions, for discriminating the six relative-intensity activity levels in female and male marathoners [39]. Once cut-off points were established, we used accelerometer output data for analyzing the running intensity distribution and energy consumption of runners during a marathon race (a free-living condition) [40]. Interestingly, accelerometer output data can also be used for inferring other useful parameters (i.e., running economy of the runner) in real conditions.

Since sex was not taken into account in our previous work, this study focused on evaluating several accelerometry-estimated parameters (energy consumption, running intensity distribution and running economy) according to the individual's sex. The use of accelerometers allowed us to directly and constantly monitor a total of 88 recreational marathon runners (74 males and 14 females) throughout the marathon race. Here, accelerometry- and pace-based data collected from females and males were analyzed separately. In this study, we also pointed out the valuable additional information that accelerometry offers to athletes, coaches and scientific community, as compared to the evaluation of running speed.

\section{Materials and Methods}

\subsection{Sample Set and Data Collection}

From all participants of the Valencia Fundación Trinidad Alfonso EDP 2016 Marathon (20 November 2016), a total of 103 recreational marathon runners, aged 30 to 45 years, were selected to participate in this study. Eight runners did not start the race and were discarded from our study population. Finally, a total of 88 recreational marathon runners (74 males and 14 females) crossed the finish line of the Valencia Fundacion Trinidad Alfonso EDP 2016 Marathon and thus were analyzed in this study. The entire process of sampling, as well as the weather and track conditions of the race, has been previously described [41].

Details of data collection, processing and analysis have been previously described [40]. Four weeks before the marathon, participants completed a cardiopulmonary test. In this appointment, we also collected anthropometric data, demographics, medical information, training program and competition history. One hour before the marathon, all participants were weighed. During the race, participants wore a GENEActiv accelerometer (Activinsights Ltd., Kimbolton, Cambridgeshire, United Kingdom) 
on the non-dominant wrist as a watch. Accelerometers were adjusted to record acceleration data at a rate of $85.7 \mathrm{~Hz}$, and data was summarized into Signal Vector Magnitude gravity subtracted (SVMgs) per minute. Recording and processing of acceleration data has been previously explained in detail [39]. All individuals underwent the same testing under the same experimental conditions. Raw data of this study is available in Supplementary File S1.

All individuals included in the current study were fully informed and gave their written consent to participate. All experiments were performed in accordance with international guidelines and regulations that govern human research. The research was approved by the Research Ethics Committee of the University Jaume I of Castellon and is enrolled in the ClinicalTrails.gov database (NCT03155633).

\subsection{Data Analysis}

The marathon race was divided into nine sections as previously described [40]. All analyses were performed for each of the nine race sections, as well as for the entire marathon distance.

Firstly, the physical effort distribution of each runner throughout the marathon, in terms of relative intensity levels of physical activity, was estimated using accelerometry-based devices and following the methodology previously described by our research group [39]. Different cut-off points were used to discriminate the six relative-intensity activity levels in female and male recreational marathoners (Table 1). Then, we estimated the time of each participant running at each one of the six-relative intensity levels (sedentary, light, moderate, vigorous, very vigorous and extremely vigorous). This estimation was performed for each of the nine race sections and for the whole race (Tables S1 and S2).

Table 1. Values established for delineating the six-relative intensity levels of physical activity according to runner's sex.

\begin{tabular}{|c|c|c|c|c|c|c|}
\hline \multirow[b]{2}{*}{ Sex } & \multirow[b]{2}{*}{$\begin{array}{l}\text { Relative-Intensity } \\
\text { Levels of Physical } \\
\text { Activity \# }\end{array}$} & \multicolumn{2}{|c|}{$\begin{array}{l}\text { Reference Values Established for Each Intensity } \\
\text { Level in Males by Hernando et al. (2018) }\end{array}$} & \multicolumn{3}{|c|}{$\begin{array}{l}\text { Values used for Energy } \\
\text { Consumption Estimation }\end{array}$} \\
\hline & & $\begin{array}{c}\mathrm{VO}_{2} \\
\left(\mathrm{~mL} \cdot \mathrm{kg}^{-1} \cdot \mathrm{min}^{-1}\right)\end{array}$ & METs * & $\begin{array}{c}\% \mathrm{VO}_{2 \max } \\
\left(\mathrm{mL} \cdot \mathrm{kg}^{-1} \cdot \mathrm{min}^{-1}\right)\end{array}$ & $\begin{array}{c}\mathrm{VO}_{2} \\
\left(\mathrm{~mL} \cdot \mathrm{kg}^{-1} \cdot \mathrm{min}^{-1}\right)\end{array}$ & METs * \\
\hline \multirow{6}{*}{ Males } & $\begin{array}{l}\text { Sedentary } \\
X<10 \%\end{array}$ & $\mathrm{VO}_{2}<5.57$ & METs $<1.59$ & 8.1 & 4.5 & 1.29 \\
\hline & $\begin{array}{c}\text { Light } \\
10 \% \leq X<25 \%\end{array}$ & $5.57 \leq \mathrm{VO}_{2}<13.94$ & $1.59 \leq \mathrm{METs}<3.97$ & 17.5 & 9.75 & 2.79 \\
\hline & $\begin{array}{c}\text { Moderate } \\
25 \% \leq X<45 \%\end{array}$ & $13.94 \leq \mathrm{VO}_{2}<25.08$ & $3.97 \leq \mathrm{METs}<7.15$ & 35.0 & 19.51 & 5.57 \\
\hline & $\begin{array}{l}\text { Vigorous } \\
45 \% \leq X<65 \%\end{array}$ & $25.08 \leq \mathrm{VO}_{2}<36.23$ & $7.15 \leq$ METs $<10.33$ & 55.0 & 30.66 & 8.76 \\
\hline & $\begin{array}{l}\text { Very Vigorous } \\
65 \% \leq X<85 \%\end{array}$ & $36.23 \leq \mathrm{VO}_{2}<47.38$ & $10.33 \leq \mathrm{METs}<13.54$ & 75.0 & 41.81 & 11.94 \\
\hline & $\begin{array}{l}\text { Extremely Vigorous } \\
\qquad X \geq 85 \%\end{array}$ & $\mathrm{VO}_{2} \geq 47.38$ & METs $\geq 13.54$ & 92.5 & 51.56 & 14.73 \\
\hline \multirow{6}{*}{ Females } & $\begin{array}{l}\text { Sedentary } \\
X<10 \%\end{array}$ & $\mathrm{VO}_{2}<4.82$ & METs $<1.38$ & 8.1 & 3.91 & 1.12 \\
\hline & $\begin{array}{l}\text { Light } \\
10 \% \leq X<25 \%\end{array}$ & $4.82 \leq \mathrm{VO}_{2}<12.07$ & $1.38 \leq \mathrm{METs}<3.45$ & 17.5 & 8.44 & 2.41 \\
\hline & $\begin{array}{c}\text { Moderate } \\
25 \% \leq X<45 \%\end{array}$ & $12.07 \leq \mathrm{VO}_{2}<21.72$ & $3.45 \leq \mathrm{METs}<6.21$ & 35.0 & 16.89 & 4.83 \\
\hline & $\begin{array}{l}\text { Vigorous } \\
45 \% \leq X<65 \%\end{array}$ & $21.72 \leq \mathrm{VO}_{2}<31.38$ & $6.21 \leq \mathrm{METs}<8.97$ & 55.0 & 26.55 & 7.59 \\
\hline & $\begin{array}{l}\text { Very Vigorous } \\
65 \% \leq X<85 \%\end{array}$ & $31.38 \leq \mathrm{VO}_{2}<41.03$ & $8.97 \leq \mathrm{METs}<11.72$ & 75.0 & 36.20 & 10.34 \\
\hline & $\begin{array}{l}\text { Extremely Vigorous } \\
\qquad X \geq 85 \%\end{array}$ & $\mathrm{VO}_{2} \geq 41.03$ & METs $\geq 11.72$ & 92.5 & 44.65 & 12.76 \\
\hline
\end{tabular}

Abbreviations: $\mathrm{N}$, number of individuals; $\mathrm{VO}_{2 \max }$, maximum oxygen consumption; $\mathrm{VO}_{2}$, oxygen consumption; MET, metabolic equivalent task. Each minute of the cardiopulmonary test was classified into one of the six intensity categories of physical activity relative to an individual's level of cardiorespiratory $\left(\mathrm{VO}_{2 \mathrm{max}}\right)$. \# X denotes the percentage of an individual's aerobic capacity $\left(\mathrm{VO}_{2 \max }\right)$ used to classify each one of the six relative-intensity categories. ${ }^{*} 1 \mathrm{MET}=3.5 \mathrm{mLO} 2 \cdot \mathrm{kg}^{-1} \cdot \mathrm{min}^{-1} .1 \mathrm{MET}=1 \mathrm{Kcal} \cdot \mathrm{h}^{-1}$.

Next, energy consumption was calculated by using the median $\% \mathrm{VO}_{2 \max }$ value of the range delimiting each intensity category in males and females (Table 1 ). That was applied for all intensity levels except for the sedentary category, in which the standing oxygen $\operatorname{cost}\left(4.5 \mathrm{mLO}_{2} \cdot \mathrm{kg}^{-1} \cdot \mathrm{min}^{-1}\right)$ was 
applied as reference value in males [42]. The reference value corresponds to the $8.1 \%$ of the maximum oxygen uptake in our males. For females, we used the $8.1 \%$ of the maximum oxygen uptake seen in our females as the $\mathrm{VO}_{2}$ standing $\left(3.91 \mathrm{mLO}_{2} \cdot \mathrm{kg}^{-1} \cdot \mathrm{min}^{-1}\right)$. Following previous recommendations [21], we considered that one MET is equal to $3.5 \mathrm{mLO} \cdot \mathrm{kg}^{-1} \cdot \mathrm{min}^{-1}$, and one MET is equal to one $\mathrm{kcal} \cdot \mathrm{kg}^{-1} \cdot \mathrm{h}^{-1}$.

As the energy consumption depends on the individual's body mass, we calculated (i) the calories consumed per kilogram of body weight per minute $\left(\mathrm{kcal} \cdot \mathrm{kg}^{-1} \cdot \mathrm{min}^{-1}\right)$, in order to obtain the physical effort intensity $[20,21,43]$; and (ii) the calories consumed per kilogram of body weight per kilometer $\left(\mathrm{kcal} \cdot \mathrm{kg}^{-1} \cdot \mathrm{km}^{-1}\right)$, to infer the running economy of runners $[16,44]$. Indeed, accelerometry-derived data was also used for estimating the $\% \mathrm{VO}_{2 \max }$ maintained during the marathon by each runner, an indicator of the physical effort degree respect to the maximum value $[19,42,43,45]$. Following the methodology described previously, we also inferred the $\mathrm{VO}_{2 \text { net }}$ and the energy of cost running above standing $\left(\mathrm{Cr}_{\text {net }}\right)$ for each participant included in the study $[12,46,47]$. These estimations were performed by applying the corresponding reference values for females and males.

The split-times in minutes of the marathon sections were recorded for calculating the average running speed of all sections and the whole marathon distance. Then, the average change in speed (ACS) for each segment, related to the average race speed, was calculated. The average change in speed through the whole race was estimated by averaging the ACS values of all sections. The ACS is a valuable measure for assessing maintenance of running pace $[9,48]$.

The squat jump test was performed to measure the runner's strength before and after the race. Jumping height was estimated using the flight time of the jump, which was measured by a contact platform (Chronojump, Barcelona, Spain) [49]. Individuals were familiarized with the test's procedure before to carry out it. Before the marathon race, all individuals performed a total of three jumps, and the best jump was recorded. After crossing the finish line, the number of attempts was conditioned by the capacity of each runner to jump (due to muscular fatigue). No more than three attempts were performed per runner, and again only the best jump was recorded.

Sex comparisons were performed by calculating the percentage of differences (gap) in all measures between males and females, as previously proposed $[7,10]$. Briefly, we applied the following formula: Gap $=\left(\left(X_{\text {females }}-X_{\text {males }}\right) / X_{\text {females }}\right) \times 100$.

\subsection{Statistical Analysis}

Statistical analyses were done using the IBM SPSS Statistics v.26 software, and null hypothesis was rejected when the two-sided $p$-value was lower than 0.05 .

The Kolgomorov-Smirnov test was used for testing data normality. Since variables were not normally distributed, all statistical analyses were performed by applying non-parametric statistical tests. The Chi-squared test was used for comparing categorical variable between males and females, while the Mann-Whitney $U$ test was applied for comparing quantitative variables between sex groups. The meaningfulness of the outcomes was additionally estimated by inferring its effect size via the calculation of Cohen's d, as following described [50,51]. Outcomes with values of $d$ lower than 0.5 were considered to have an small relevance; those with $\mathrm{d}$ values between 0.5 and 0.8 presented moderate relevance; and those with values greater than 0.8 had large significance [52].

\section{Results}

A detailed description of individuals included in this study is summarized in Table 2. Sex differences were observed for several physiological traits, such as the body mass index (BMI; $p$-value $=0.001$ ), the percentage of body fat $\left(p\right.$-value $\left.=2.03 \times 10^{-5}\right)$, the maximum oxygen uptake $\left(\mathrm{VO}_{2 \max } ; p\right.$-value $=$ $\left.6.59 \times 10^{-6}\right)$, and the maximum metabolic equivalent of task $\left(\mathrm{MET}\right.$; $p$-value $\left.=6.77 \times 10^{-6}\right)$. Moreover, sex differences were also observed in the sessions of training performed per week ( $p$-value $=0.04$ ) and in the number of marathons completed ( $p$-value $=0.03$ ). 
Table 2. Population description.

\begin{tabular}{|c|c|c|c|c|}
\hline & riables & Males $(\mathrm{N}=74)$ & Females $(\mathrm{N}=14)$ & $p$-Value \\
\hline \multirow{5}{*}{$\begin{array}{l}\text { Physiological } \\
\text { characteristics* }\end{array}$} & age & $38.58 \pm 3.70$ & $39.21 \pm 3.14$ & 0.61 \\
\hline & BMI & $23.15 \pm 1.46$ & $21.65 \pm 1.93$ & 0.001 \\
\hline & $\%$ body fat & $13.76 \pm 3.68$ & $19.94 \pm 4.26$ & $2.03 \times 10^{-5}$ \\
\hline & $\mathrm{VO}_{2 \max }\left(\mathrm{mL} \cdot \mathrm{kg}^{-1} \cdot \mathrm{min}^{-1}\right)$ & $55.55 \pm 5.25$ & $48.39 \pm 3.60$ & $6.59 \times 10^{-6}$ \\
\hline & maximum METs & $15.87 \pm 1.50$ & $13.83 \pm 1.03$ & $6.77 \times 10^{-6}$ \\
\hline \multirow{4}{*}{$\begin{array}{l}\text { Training } \\
\text { indicators * }\end{array}$} & years of running & $6.42 \pm 2.89$ & $6.43 \pm 2.17$ & 0.99 \\
\hline & sessions per week & $4.97 \pm 0.83$ & $4.50 \pm 0.76$ & 0.04 \\
\hline & kilometers per week & $64.32 \pm 13.16$ & $58.93 \pm 11.96$ & 0.14 \\
\hline & hours per week & $7.54 \pm 2.57$ & $6.46 \pm 1.82$ & 0.16 \\
\hline \multirow{2}{*}{$\begin{array}{l}\text { History as } \\
\text { marathoner * }\end{array}$} & marathons finished & $3.62 \pm 3.11$ & $2.00 \pm 2.15$ & 0.03 \\
\hline & marathon per year & $1.12 \pm 0.64$ & $1.00 \pm 0.55$ & 0.58 \\
\hline \multirow{3}{*}{ Work intensity \# } & high intensity & $9.46 \%$ & $0.00 \%$ & \multirow{3}{*}{0.44} \\
\hline & medium intensity & $31.08 \%$ & $28.57 \%$ & \\
\hline & low intensity & $59.46 \%$ & $71.43 \%$ & \\
\hline \multirow{4}{*}{ Levels of study \# } & school graduate & $4.11 \%$ & $7.14 \%$ & \multirow{4}{*}{0.72} \\
\hline & high school graduate & $19.18 \%$ & $7.14 \%$ & \\
\hline & professional certificate & $6.85 \%$ & $7.14 \%$ & \\
\hline & undergraduate degree & $69.86 \%$ & $78.57 \%$ & \\
\hline
\end{tabular}

Abbreviations: N, number of samples; BMI, body mass index; SD, standard deviation. ${ }^{*}$ Values are presented as mean \pm SD. \#. Values are presented as percentage. Mann-Whitney $U$ test was used for comparing quantitative variables among groups. Chi-square test was used for comparing categorical variables among groups. Bold denotes significant results.

Using the squat jump test, we measured the level of lower body strength of each runner before and after running the marathon (Table 3). As expected, the basal squat jump height was significantly higher in males compared to females $(27.34 \pm 4.28 \mathrm{~cm}$ versus $23.84 \pm 3.82 \mathrm{~cm}$; $p$-value $=0.007$; Cohen's $\mathrm{d}=0.60$ ). No significant sex differences in the squat jump height were observed after crossing the finish line $(21.88 \pm 6.19 \mathrm{~cm}$ versus $20.53 \pm 6.72 \mathrm{~cm}$; $p$-value $=0.300$; Cohen's $\mathrm{d}=0.22)$. Therefore, the lower body strength of females seemed to be less altered by running a marathon, one of the most challenging endurance competitions.

Table 3. Comparison of the different variables collected over the whole marathon distance between males and females.

\begin{tabular}{|c|c|c|c|c|c|}
\hline Variable & Males $(\mathbf{N}=74)$ & Females $(\mathrm{N}=14)$ & $p$-Value & Cohen's $d$ & Gap \\
\hline Speed $\left(\mathrm{m} \cdot \mathrm{min}^{-1}\right)$ & $201.29 \pm 17.84$ & $180.96 \pm 14.07$ & $1.74 \times 10^{-4}$ & 0.87 & $-11.24 \%$ \\
\hline Energy consumed (kcal) & $3274.07 \pm 599.82$ & $2423.01 \pm 239.76$ & $9.32 \times 10^{-7}$ & 1.23 & $-35.12 \%$ \\
\hline $\begin{array}{l}\text { Relative energy consumed per minute } \\
\qquad\left(\mathrm{kcal} \cdot \mathrm{kg}^{-1} \cdot \mathrm{min}^{-1}\right)\end{array}$ & $0.21 \pm 0.03$ & $0.19 \pm 0.02$ & $9.91 \times 10^{-4}$ & 0.75 & $-14.42 \%$ \\
\hline $\begin{array}{l}\text { Relative energy consumed per kilometer } \\
\qquad\left(\mathrm{kcal} \cdot \mathrm{kg}^{-1} \cdot \mathrm{km}^{-1}\right)\end{array}$ & $1.07 \pm 0.16$ & $1.04 \pm 0.11$ & 0.34 & 0.21 & $-2.91 \%$ \\
\hline Basal Metabolic Rate (BMR) & $12.87 \pm 1.84$ & $11.24 \pm 1.06$ & $8.29 \times 10^{-4}$ & 0.76 & $-14.47 \%$ \\
\hline Marathon time (minutes) & $211.28 \pm 19.16$ & $234.50 \pm 18.46$ & $1.74 \times 10^{-4}$ & 0.87 & $9.90 \%$ \\
\hline Squat jump at the start line $(\mathrm{cm})$ & $27.24 \pm 4.29$ & $23.84 \pm 3.82$ & 0.007 & 0.60 & $-14.26 \%$ \\
\hline Squat jump at the finish line $(\mathrm{cm})$ & $21.89 \pm 6.19$ & $20.53 \pm 6.72$ & 0.30 & 0.22 & $-6.62 \%$ \\
\hline Average change in speed (\%) & $5.39 \pm 2.62$ & $6.29 \pm 2.58$ & 0.15 & 0.31 & $14 \%$ \\
\hline$\%$ of time at sedentary level & $0.01 \pm 0.12$ & $0.00 \pm 0.00$ & 0.66 & 0.02 & NA \\
\hline$\%$ of time at extremely vigorous level & $53.88 \pm 39.29$ & $43.64 \pm 34.86$ & 0.27 & 0.24 & $-23 \%$ \\
\hline
\end{tabular}

Abbreviations: N, number of samples; SD, standard deviation; NA, not available; Gap, percentage of sex differences. Values are presented as mean $\pm \mathrm{SD}$. Mann-Whitney $\mathrm{U}$ test was used for comparing quantitative variables among groups. Cohen's $d$ was calculated for inferring the effect size of a variable. Bold denotes significant results. 
Firstly, accelerometer-derived data was used to determine the running intensity distribution of female and male runners throughout the marathon. In this regard, the time consumed at each intensity level was expressed as the percentage respect to the total time needed for covering each one of the nine race sections and to the marathon time (Figure 1 and Table 3).
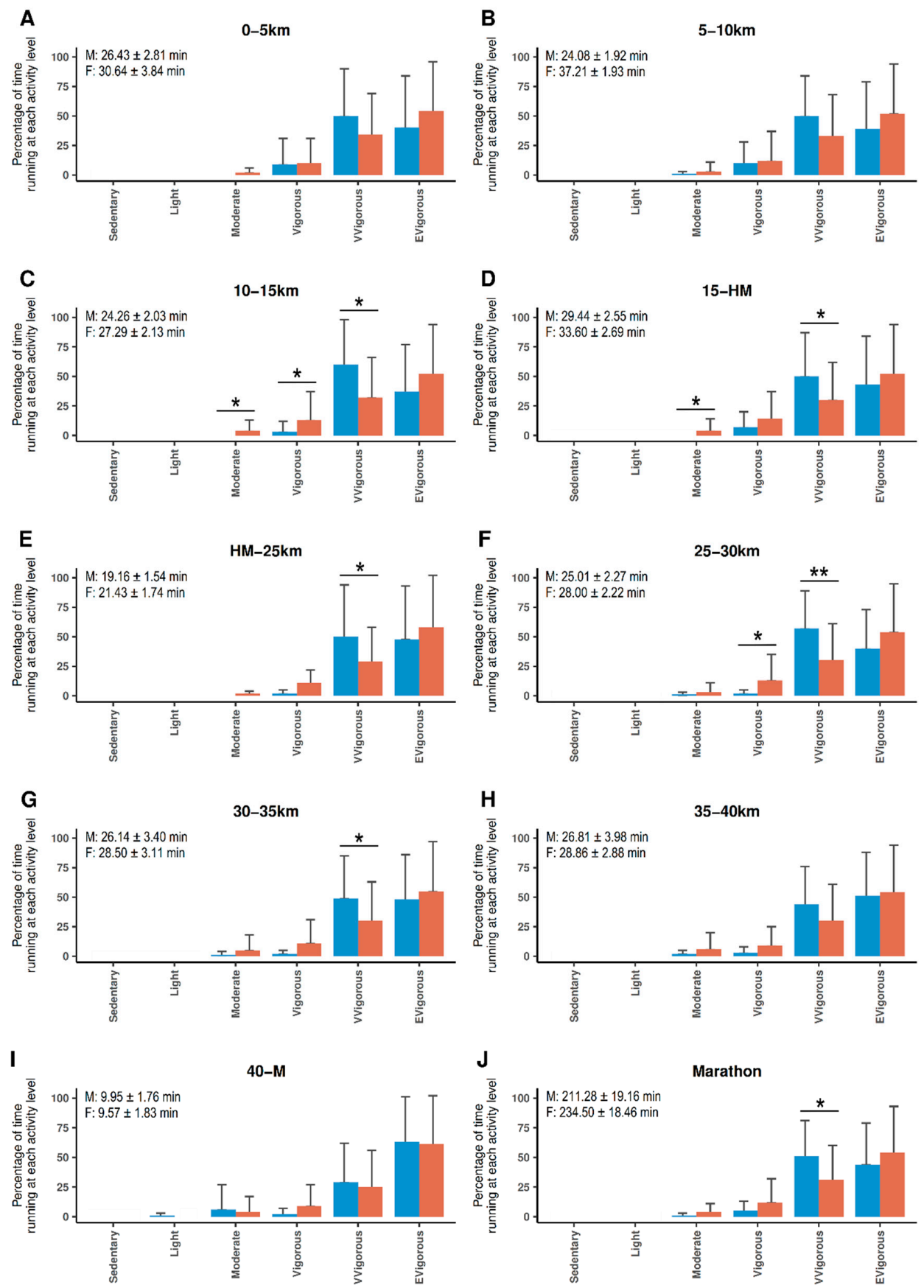

Figure 1. Bar plots showing the percentage of time performing at each of the six-relative intensity levels of physical activity. Running intensity distribution was analyzed (A-I) in each one of the nine race sections, and $(\mathbf{J})$ for the whole marathon distance. Bars represent the average values for males (orange) and females (blue), and error bars represent the standard deviation of the mean. Mean time spent ( \pm standard deviation) to cover each race sections and the whole race by males $(\mathrm{M})$ and females (F) is showed in the corresponding panel. A Mann-Whitney $U$ test was used for testing sex differences. ${ }^{*} p$-value $<0.05 ;{ }^{* *} p$-value $<0.01$. 
Time racing at extremely vigorous intensity level was similar in females and males at all race sections and in the entire marathon distance (Figure 1 and Table 3). However, males tended to spend more time running at extremely vigorous intensity than females, except for the last race section (from $40 \mathrm{~km}$ to the finish line) $(61.05 \pm 40.69 \%$ versus $62.93 \pm 38.08 \%$, respectively). Regarding the distribution of time running at the very vigorous intensity level, females seemed to spend a higher percentage of time running at this intensity level than males, with significant differences in the 10-15 km section, the $15-\mathrm{HM}$ section, the HM- $25 \mathrm{~km}$ section, the $25-30 \mathrm{~km}$ section, the $30-35 \mathrm{~km}$ section and the entire marathon distance (Figure 1 and Table 3 ).

Nevertheless, males were more time running at vigorous intensity than females, showing significant differences in the $10-15 \mathrm{~km}$ and the $25-30 \mathrm{~km}$ race sections (Figure 1). There were sex differences in the percentage of time running at moderate intensity in the 10-15 km and the $15-\mathrm{HM}$ race sections, with males presenting higher values than females. As for the extremely vigorous level of physical intensity, females showed a higher, but not significantly, percentage of time running at moderate intensity than males in the last race section (from $40 \mathrm{~km}$ to the finish line) (5.50 $\pm 20.58 \%$ versus $4.41 \pm 13.23 \%$, respectively).

As expected by the conditions of the activity, the percentage of time running at both sedentary and light intensities was minimum for both males and females. In fact, the time running at the two highest intensity levels (very vigorous and extremely vigorous) represented the $84.95 \pm 23.70 \%$ of the marathon time for males and the $94.21 \pm 9.64 \%$ for females (Figure 2). Therefore, running at these high intensities is crucial for achieving the marathon goal time of runners. The differences in absolute percentages denoted that females had a minimum decay rate in their running intensity, while males tended to drop from running at a very high intensity level (mainly at extremely vigorous) to a vigorous intensity level.

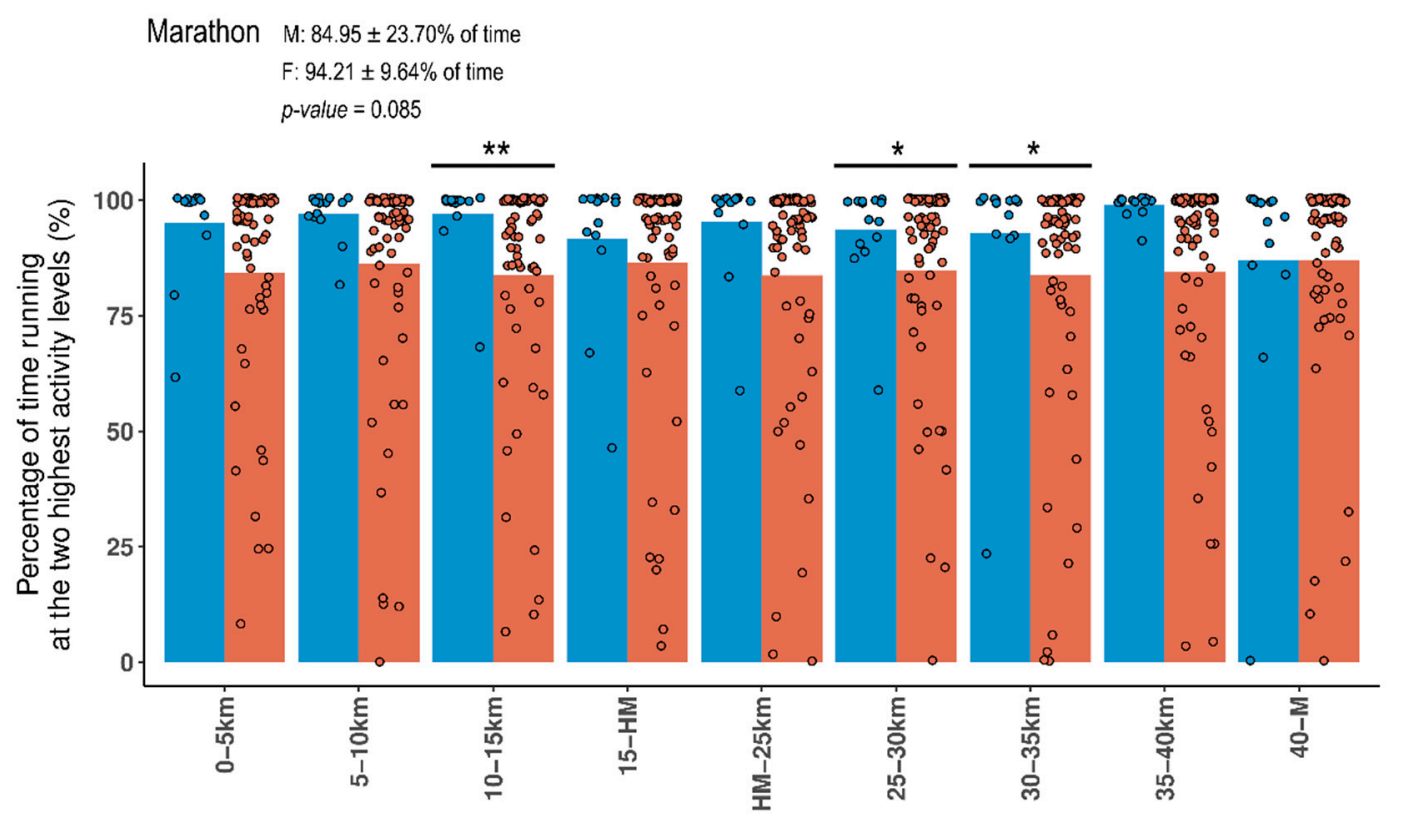

Figure 2. Bar plot showing the percentage of time performing at the two highest intensity levels of physical activity. Bars represent the average values for males (orange) and females (blue). Dots represent each runner included in our study. Mean percentage ( \pm standard deviation) of time performing at these intensity levels is showed in the corresponding panel. A Mann-Whitney $U$ test was used for testing differences between females $(\mathrm{F})$ and males $(\mathrm{M}) .{ }^{*} p$-value $<0.05 ;{ }^{* *} p$-value $<0.01$.

We also compared the evolution of running speed throughout the marathon race (Figure $3 \mathrm{~A}$ and Table 3). Overall, running speed was higher in males than in females, except for the last section of the race (from $40 \mathrm{~km}$ to the finish line) $\left(238.16 \pm 51.50 \mathrm{~m} \cdot \mathrm{min}^{-1}\right.$ for females versus $227.44 \pm 40.16 \mathrm{~m} \cdot \mathrm{min}^{-1}$ for males). In fact, the Gap (percentage of the relative sex difference) in running speed was decreasing 
during the course of the marathon. For the entire marathon distance, the running speed of females was an $11.24 \%$ slower than males (Gap $=-11.24 \%$ ). However, a positive Gap value (4.50\%) was obtained in the last race section (from $40 \mathrm{~km}$ to the finish line), denoting the faster speed achieved by females compared to males in the last kilometers.

A

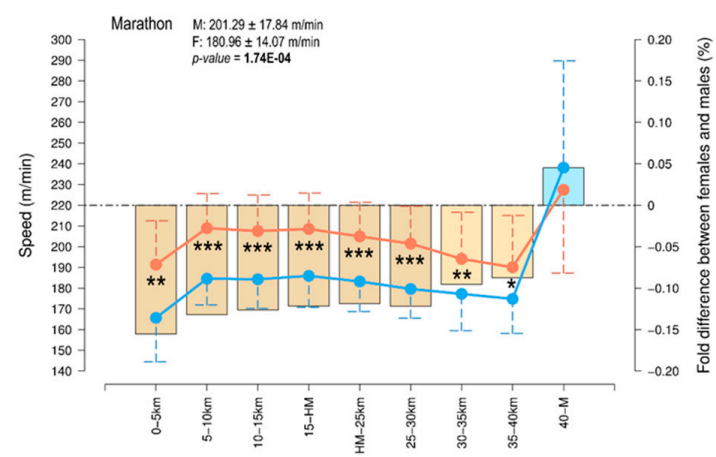

C

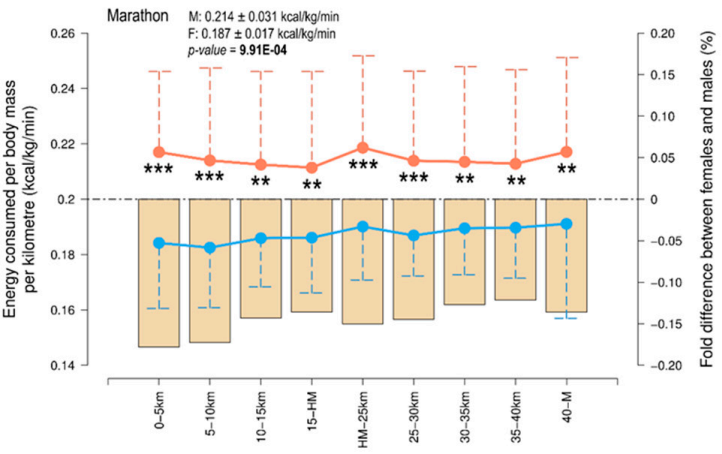

E

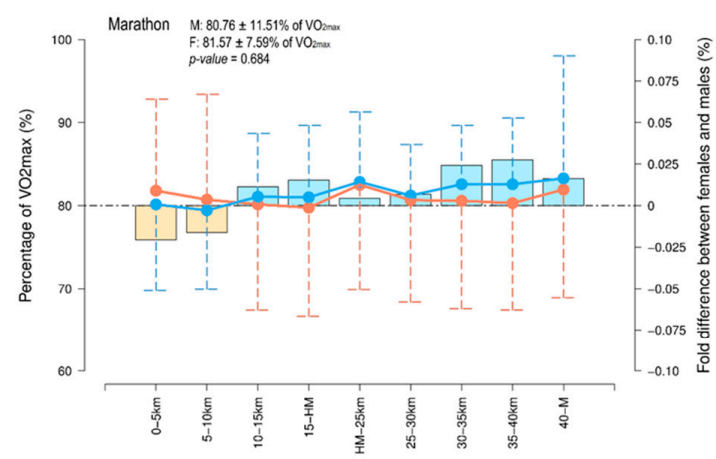

B

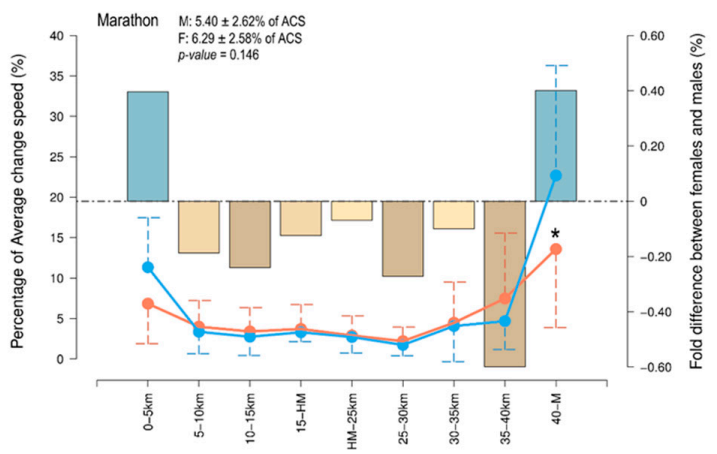

D

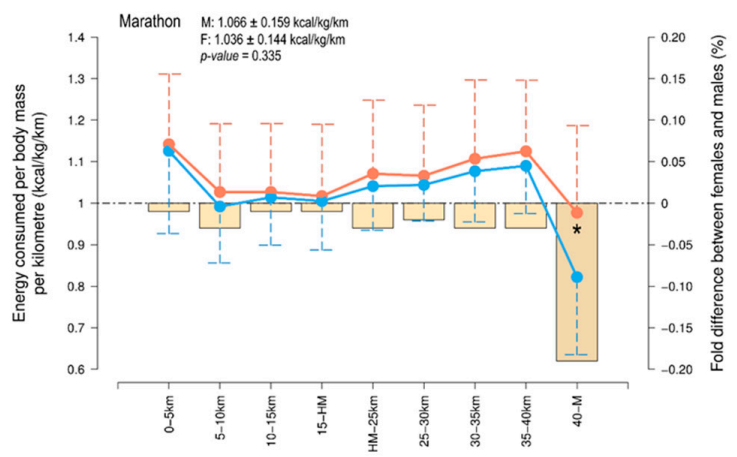

$\mathbf{F}$

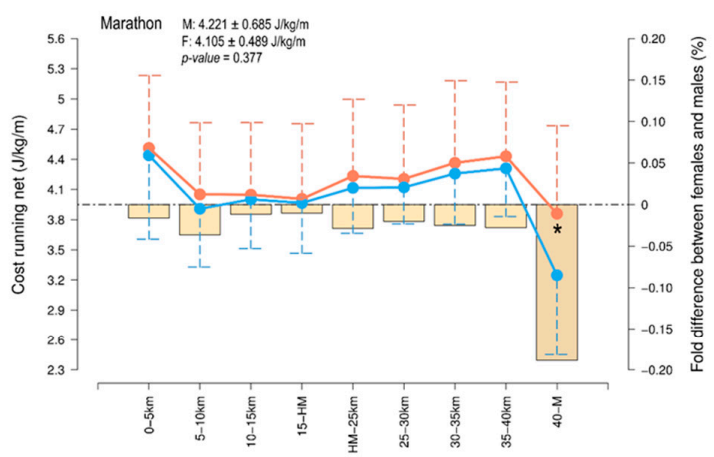

\begin{tabular}{|c|c|c|c|}
\hline Sexes & \multirow{2}{*}{\multicolumn{3}{|c|}{$\begin{array}{l}\text { Percentage of fold differences } \\
\text { between females and males }\end{array}$}} \\
\hline$\multimap$ Females & $\square$ from -0.10 to $0 \%$ & $\square$ trom 0 to $0.10 \%$ & \\
\hline & $\square$ from $-0.2010-0.10 \%$ & $\square$ from 0.10 to $0.20 \%$ & $\star *$ p-value $<0.01$ \\
\hline Males & $\square$ Iower than $-0.20 \%$ & $\square$ higher than $0.20 \%$ & $\star \star \star$ p-value $<0.001$ \\
\hline
\end{tabular}

Figure 3. Evolution of (A) speed, (B) percentage of average change speed, (C) relative energy consumed per minute, (D) relative energy consumed per kilometer, (E) percentage of maximum oxygen uptake, and (F) cost running above the standing level. Dots represent the average values for males (orange) and females (blue), and error bars represent the standard deviation of the mean. Bars represent the percentage of sex difference (Gap). Mean values ( \pm standard deviation) of each variable analyzed for the whole marathon distance are showed in the corresponding panel. A Mann-Whitney U test was used for testing sex differences. Bold denotes significant differences in values obtained for the whole marathon distance between females (F) and males (M). 
Additionally, we evaluated the evolution of ACS (Figure 3B). Results denoted higher changes of speed in females compared to males $(6.29 \pm 2.58$ versus $5.40 \pm 2.62$, respectively). This observation is mainly caused by the significant increase of running speed made by females in the last section of the race. In fact, ACS values were lower in females compared to males $(4.24 \pm 1.75$ versus $4.37 \pm 2.68$, respectively) when the ACS was evaluated without taking into account the last race section. That is, running pace of females was more stable than males in the first $40 \mathrm{~km}$ of the race and, for that reason, they were able to sprint in the last section of the marathon. Our results denoted significant sex differences in the ACS only in this last section of the race (the unique race section without significantly sex differences in the absolute running speed; Figure 3A).

Energy consumption was also compared between females and males. Males consumed $12 \%$ to $18 \%$ more energy (kilocalories normalized per body mass) per minute than females at all marathon sections (Figure $3 \mathrm{C}$ ) and in the entire race distance (Table 3).

Accelerometry-derived data was also used to estimate the $\% \mathrm{VO}_{2 \max }$ sustained throughout the race by each runner, following the methodology previously published by our research group [38]. Females and males consumed a similar $\% \mathrm{VO}_{2 \max }$ at the different race sections analyzed (Figure $3 \mathrm{E}$ ). Besides, very similar overall values were observed in males $\left(80.76 \pm 11.51 \%\right.$ of $\left.\mathrm{VO}_{2 \max }\right)$ and females $\left(81.57 \pm 7.59 \%\right.$ of $\mathrm{VO}_{2 \max }$ ) (Table 3). However, it is noted that females needed to maintain a slightly higher $\% \mathrm{VO}_{2 \mathrm{max}}$ for running at a lower running intensity level in comparison to males (at very vigorous and at extremely vigorous intensity for females and males, respectively).

Running economy was measured by estimating both the energy (kilocalories normalized by body mass) consumed per kilometer and the Cost running above standing $\left(\mathrm{Cr}_{\text {net }}\right)$. As expected for the last section of the race, no differences were observed in running economy between male and female runners, independently of the method used (Figure 3D,F, and Table 3). Females seemed to have better running economy than males in the last race section (from $40 \mathrm{~km}$ to the finish line), which is denoted by: (i) females consumed less energy per kilometer than males $\left(0.822 \pm 0.187 \mathrm{kcal} \cdot \mathrm{kg}^{-1} \cdot \mathrm{km}^{-1}\right.$ versus $0.977 \pm 0.210 \mathrm{kcal} \cdot \mathrm{kg}^{-1} \cdot \mathrm{km}^{-1} ; p$-value $=0.017 ;$ Cohen's $\mathrm{d}=0.53$ ), and (ii) females presented a lower $\mathrm{Cr}_{\text {net }}$ than males $\left(3248 \pm 0.794 \mathrm{j} \cdot \mathrm{kg}^{-1} \cdot \mathrm{m}^{-1}\right.$ versus $3860 \pm 0.875 \mathrm{j} \cdot \mathrm{kg}^{-1} \cdot \mathrm{m}^{-1} ; p$-value $=0.022$; Cohen's $d=0.51)$. Maximum Gap values were observed in the last race section for both variables $(-18.89 \%$ for $\mathrm{kcal} \cdot \mathrm{kg}^{-1} \cdot \mathrm{km}^{-1}$; and $-18.85 \%$ for $\mathrm{Cr}_{\text {net }}$ ). In this race section, the negative values of Gap denoted that males consumed more energy per distance (and therefore presented a lower running economy) than females.

\section{Discussion}

This observational study aimed at increasing our understanding on how females and males achieve their marathon goal. In this regard, we focused on analyzing the evolution of several accelerometryestimated parameters (energy consumption, running intensity distribution, running economy, oxygen uptake), as well as pace-related variables (running speed, average change in speed), throughout a marathon race taking into account runner's sex. For this purpose, we directly monitored female and male recreational runners throughout the entire marathon distance by using accelerometer-based devices. Moreover, we also collected split times of each runner (provided by the organizers of the Valencia Marathon).

Similar to previous studies $[4,53]$, the average running speed was significantly higher in males compared to females. In this study, the difference rate in running speed between males and females was $11.24 \%$. This percentage matched with values obtained in previous studies, which ranged from $8 \%$ to $14 \%[4-6,8,10,17]$. However, this percentage of sex difference seems to be lower in elite compared to amateur marathoners. In fact, the female marathon world record (2:14:09, Brigid Kosgei, Chicago 2019) is only $9.32 \%$ slower than the male marathon world record (2:01:39, Eliud Kipchoge, Berlin 2018).

Sex variability in marathon performance may be explained by the well-known differences in several physiological traits [4,53-55]. Descriptive analyses showed that males presented higher maximum oxygen uptake, body mass index, muscle strength, and lower percentage of body fat than 
females. Muscle strength has been shown to determine the runner's ability of displacement and thus running speed. In fact, a lower percentage of sex difference has been observed for swimming speed (6-7\%), a physical activity in which the muscle strength component is considerably less crucial for succeeding compared to running [56,57].

However, according to the split times collected of each runner, males were more likely to slow their pace in the last part of the marathon race than females. Males started the marathon running at a $15.53 \%$ faster speed than females in the first race section (from start line to $5 \mathrm{~km}$ ), and this difference rate was decreasing throughout the marathon. In fact, females run at $4.5 \%$ faster speed than males in the last marathon section (from $40 \mathrm{~km}$ to finish line). Additionally, by analyzing the ACS [9], we were able to confirm that females raced at a more constant pace from the start line to the $40 \mathrm{~km}$ as compared to males. This pace strategy may allow females to significantly increase their running speed in the last section of the race, while males were more likely to "hit the wall" in the last kilometers.

At this point, we would like to highlight the notably difference in the running speed maintained by males and females in the first section of the race (Gap of $-15.53 \%$ ). This difference may be attributed to the fact that, in races with more than 20,000 participants, runners cannot run the first kilometers freely without difficulty due to the large number of participants and the limited space. This notable sex difference may thus indicate that males started the race being more ambitious, while females adopted a more cautious attitude $[54,55,58]$. This observation was not previously seen by Nikolaidis and cols (2019) [9], probably because they split the race distance into $10 \mathrm{~km}$ sectors and not in $5 \mathrm{~km}$ sectors as we did in this work. Having shorter sections allowed us to observe changes in running pace and intensity in greater detail.

To further explore sex differences in marathon performance, and taking into account that there is a lack of gold standard for measuring energy consumption in free-living conditions (as a marathon race) [40], we used accelerometer-based devises for estimating the distribution of physical effort throughout the marathon according to runner's sex [39]. Specifically, we estimated the time running at each of the six-relative intensity levels (sedentary, light, moderate, vigorous, very vigorous and extremely vigorous) in each one of the nine race sections and in the entire marathon. The analysis of physical effort distribution denoted that females tended to race at a lower intensity level than males (females significantly ran more percentage of time at very vigorous intensity than males, who mainly ran at extremely vigorous intensity).

In addition, accelerometry-based data allowed us to estimate the energy consumed and the $\% \mathrm{VO}_{2 \max }$ sustained per each runner, and afterwards his/her running economy. According to our results, females reported a better efficiency of movement than males in the last section of the marathon (from $40 \mathrm{~km}$ to the finish line). That is, a superior energy was demanded by males for running at a given speed the last $2.195 \mathrm{~km}$ of the marathon. This may be a consequence of the high physical effort sustained by males in the first part of the marathon, pointing out the importance of controlling physical effort distribution in a marathon race to avoid "hitting the wall". Running at high intensities has been shown to accelerate glycolytic depletion [55], which may contribute to the decrease of running pace observed in males in the last part of the marathon. Females, however, may use fats as principal energy source maintaining their glycogen stores in muscles thanks to running at less demanding intensities. As stated in lab-based conditions [13], females may present lower respiratory exchange ratio (RER) compared to males, indicating in turn that fat may be the principal fuel source used by females. Future work may be focused on validating accelerometry for RER estimations.

Two limitations are noteworthy in the present study. Firstly, we are aware about the low number of females included in our population (15.91\%). However, this percentage is even higher than the rate of females, aged 30 to 45 years, finishing the Valencia Marathon in 2016 (13.16\%). Higher effort should be done in future studies for increasing the number of females collected. The second limitation is that values of accelerometer-based parameters analyzed in this study were merely estimations. No gold standard method is available yet to perform a direct measurement of $\mathrm{VO}_{2}$ consumed by a runner in free-living conditions. We may assume a plausible maximum error of $10 \%$ in our estimations. 
In summary, thanks to the accelerometry-based and pace-based data collected, this study reveals how female and male middle-aged amateur marathoners face a marathon in terms of pacing, running strategy, running intensity distribution, energy consumption and running economy. The use of accelerometer devices for monitoring runners allowed us to perform an individualized assessment in the context of free-living movement. In general, females showed a good control of physical effort throughout the marathon, while the running intensity distribution and pacing of males were not so well-balanced. Subsequently, an increased decay of running pace in the last part of the marathon was observed for males. Results may reflect well-known sex differences in physiology (i.e., muscle strength, fat metabolism, $\mathrm{VO}_{2 \max }$ ), and in running strategy approach (i.e., females run at a more conservative intensity level in the first part of the marathon compared to males).

\section{Conclusions}

Compared to males, females maintained a more stable pace and ran at less demanding running intensities throughout the marathon, limiting the decay of running pace in the last part of the race. Together with previous studies, the results obtained after analyzing a huge number of variables suggest that the steady pacing of females may be because of the following reasons:

- $\quad$ Females may manage energy during the race more efficiently than males [7,55].

- Females may make better decisions in terms of pacing strategy than males $[6,48,54]$.

- Females typically use more fat than carbohydrates during endurance exercise compared to males $[14,59,60]$.

- Females tend to preserve muscle strength and have less neuromuscular fatigue than males at the end of the marathon [61].

Supplementary Materials: The following are available online at http://www.mdpi.com/1660-4601/17/17/6196/s1. Table S1: Evaluation of running intensity distribution and estimation of calories consumed by male runners based on accelerometry data. Table S2: Evaluation of running intensity distribution and estimation of calories consumed by male runners based on accelerometry data. File S1: Raw data of the study.

Data Availability: All data generated or analyzed during this study are included in this published article (and its Supplementary Materials).

Author Contributions: C.H. (Carlos Hernando) and B.H. contributed to conception and design of the study, article drafting and critical revision of the article. C.H. (Carlos Hernando) and C.H. (Carla Hernando) contributed to data curation, analysis and interpretation. C.H. (Carlos Hernando), I.M.-N., E.C.-B. and N.P. contributed to data collection and critical revision of the article. C.H. (Carlos Hernando), I.M.-N. and E.C.-B. contributed to funding acquisition. All authors have read and agreed to the published version of the manuscript.

Funding: This research was funded by the Fundacion Trinidad Alfonso, the Vithas-Nisa Hospitals group and the Sociedad Deportiva Correcaminos.

Acknowledgments: We are grateful to all the stuff involved in the organization of the Valencia Marathon Fundacion Trinidad Alfonso EDP 2016, and all marathoners and volunteers participating in this study.

Conflicts of Interest: The authors declare no conflict of interest.

\section{References}

1. Ahmadyar, B.; Rüst, C.A.; Rosemann, T.; Knechtle, B. Participation and performance trends in elderly marathoners in four of the world's largest marathons during 2004-2011. SpringerPlus 2015, 4, 465. [CrossRef] [PubMed]

2. Aschmann, A.; Knechtle, B.; Onywera, V.O.; Nikolaidis, P.T. Pacing Strategies in the New York City Marathon-Does Nationality of Finishers Matter? (Request PDF). Asian J. Sports Med. 2018. [CrossRef]

3. Maratón de Valencia Fundación Trinidad Alfonso EDP. Available online: https://www.valenciaciudaddelrunning. com/maraton/ediciones-anteriores-maraton/ (accessed on 18 November 2019).

4. Joyner, M.J. Physiological limits to endurance exercise performance: Influence of sex. J. Physiol. 2017, 595, 2949-2954. [CrossRef]

5. Eichenberger, E.; Knechtle, B.; Rüst, C.A.; Rosemann, T.; Lepers, R. Age and sex interactions in mountain ultramarathon running-The Swiss Alpine Marathon. Open Access J. Sports Med. 2012, 3, 73-80. [CrossRef] 
6. Nikolaidis, P.T.; Onywera, V.O.; Knechtle, B. Running Performance, Nationality, Sex, and Age in the 10-km, Half-Marathon, Marathon, and the 100-km Ultramarathon IAAF 1999-2015. J. Strength Cond. Res. 2017, 31, 2189-2207. [CrossRef]

7. Senefeld, J.; Smith, C.; Hunter, S.K. Sex Differences in Participation, Performance, and Age of Ultramarathon Runners. Int. J. Sports Physiol. Perform. 2016, 11, 635-642. [CrossRef] [PubMed]

8. Zavorsky, G.S.; Tomko, K.A.; Smoliga, J.M. Declines in marathon performance: Sex differences in elite and recreational athletes. PLoS ONE 2017, 12, e0172121. [CrossRef]

9. Nikolaidis, P.T.; Rosemann, T.; Cuk, I.; Knechtle, B. Performance and Pacing of Age Groups in Half-Marathon and Marathon. Int. J. Environ. Res. Public Health 2019, 16, 1777. [CrossRef]

10. Cheuvront, S.N.; Carter, R.; Deruisseau, K.C.; Moffatt, R.J. Running performance differences between men and women:an update. Sports Med. Auckl. N. Z. 2005, 35, 1017-1024. [CrossRef]

11. Helgerud, J.; Støren, Ø.; Hoff, J. Are there differences in running economy at different velocities for well-trained distance runners? Eur. J. Appl. Physiol. 2010, 108, 1099-1105. [CrossRef]

12. di Prampero, P.E.; Atchou, G.; Brückner, J.C.; Moia, C. The energetics of endurance running. Eur. J. Appl. Physiol. 1986, 55, 259-266. [CrossRef] [PubMed]

13. Loftin, M.; Sothern, M.; Tuuri, G.; Tompkins, C.; Koss, C.; Bonis, M. Gender comparison of physiologic and perceptual responses in recreational marathon runners. Int. J. Sports Physiol. Perform. 2009, 4, 307-316. [CrossRef] [PubMed]

14. Tarnopolsky, M.A.; Atkinson, S.A.; Phillips, S.M.; MacDougall, J.D. Carbohydrate loading and metabolism during exercise in men and women. J. Appl. Physiol. (Bethesda Md. 1985) 1995, 78, 1360-1368. [CrossRef]

15. Barnes, K.R.; Kilding, A.E. Running economy: Measurement, norms, and determining factors. Sports Med. Open 2015, 1, 8. [CrossRef] [PubMed]

16. di Prampero, P.E. Factors limiting maximal performance in humans. Eur. J. Appl. Physiol. 2003, 90, 420-429. [CrossRef]

17. Saunders, P.U.; Pyne, D.B.; Telford, R.D.; Hawley, J.A. Factors Affecting Running Economy in Trained Distance Runners. Sports Med. 2004, 34, 465-485. [CrossRef]

18. Nikolaidis, P.T.; Rosemann, T.; Knechtle, B. A Brief Review of Personality in Marathon Runners: The Role of Sex, Age and Performance Level. Sports (Basel Switz.) 2018, 6, 99. [CrossRef]

19. McLellan, T.M.; Skinner, J.S. Submaximal endurance performance related to the ventilation thresholds. Can. J. Appl. Sport Sci. 1985, 10, 81-87.

20. Ainsworth, B.E.; Haskell, W.L.; Leon, A.S.; Jacobs, D.R.; Montoye, H.J.; Sallis, J.F.; Paffenbarger, R.S. Compendium of physical activities: Classification of energy costs of human physical activities. Med. Sci. Sports Exerc. 1993, 25, 71-80. [CrossRef]

21. Ainsworth, B.E.; Haskell, W.L.; Whitt, M.C.; Irwin, M.L.; Swartz, A.M.; Strath, S.J.; O’Brien, W.L.; Bassett, D.R.; Schmitz, K.H.; Emplaincourt, P.O.; et al. Compendium of physical activities: An update of activity codes and MET intensities. Med. Sci. Sports Exerc. 2000, 32, S498-S504. [CrossRef]

22. Ainsworth, B.E.; Haskell, W.L.; Herrmann, S.D.; Meckes, N.; Bassett, D.R.; Tudor-Locke, C.; Greer, J.L.; Vezina, J.; Whitt-Glover, M.C.; Leon, A.S. 2011 Compendium of Physical Activities: A second update of codes and MET values. Med. Sci. Sports Exerc. 2011, 43, 1575-1581. [CrossRef]

23. Davies, M.J.; Mahar, M.T.; Cunningham, L.N. Running economy: Comparison of body mass adjustment methods. Res. Q. Exerc. Sport 1997, 68, 177-181. [CrossRef] [PubMed]

24. Klepin, K.; Wing, D.; Higgins, M.; Nichols, J.; Godino, J.G. Validity of Cardiorespiratory Fitness Measured with Fitbit Compared to VO2max. Med. Sci. Sports Exerc. 2019. [CrossRef] [PubMed]

25. Sperlich, B.; Aminian, K.; Düking, P.; Holmberg, H.-C. Editorial: Wearable Sensor Technology for Monitoring Training Load and Health in the Athletic Population. Front. Physiol. 2019, 10, 1520. [CrossRef] [PubMed]

26. Kinnunen, H.; Häkkinen, K.; Schumann, M.; Karavirta, L.; Westerterp, K.R.; Kyröläinen, H. Training-induced changes in daily energy expenditure: Methodological evaluation using wrist-worn accelerometer, heart rate monitor, and doubly labeled water technique. PLoS ONE 2019, 14, e219563. [CrossRef] [PubMed]

27. Tudor-Locke, C.; Aguiar, E.J.; Han, H.; Ducharme, S.W.; Schuna, J.M.; Barreira, T.V.; Moore, C.C.; Busa, M.A.; Lim, J.; Sirard, J.R.; et al. Walking cadence (steps/min) and intensity in 21-40 year olds: CADENCE-adults. Int. J. Behav. Nutr. Phys. Act. 2019, 16, 8. [CrossRef] [PubMed] 
28. Suchert, V.; Isensee, B.; Sargent, J.; Weisser, B.; Hanewinkel, R.; Läuft Study Group. Prospective effects of pedometer use and class competitions on physical activity in youth: A cluster-randomized controlled trial. Prev. Med. 2015, 81, 399-404. [CrossRef]

29. Clevenger, K.A.; Molesky, M.J.; Vusich, J.; Montoye, A.H.K. Free-Living Comparison of Physical Activity and Sleep Data from Fitbit Activity Trackers Worn on the Dominant and Nondominant Wrists. Meas. Phys. Educ. Exerc. Sci. 2019, 23, 194-204. [CrossRef]

30. Montoye, H.J.; Washburn, R.; Servais, S.; Ertl, A.; Webster, J.G.; Nagle, F.J. Estimation of energy expenditure by a portable accelerometer. Med. Sci. Sports Exerc. 1983, 15, 403-407. [CrossRef]

31. Smith, M.P.; Horsch, A.; Standl, M.; Heinrich, J.; Schulz, H. Uni- and triaxial accelerometric signals agree during daily routine, but show differences between sports. Sci. Rep. 2018, 8, 15055. [CrossRef]

32. Strath, S.J.; Kaminsky, L.A.; Ainsworth, B.E.; Ekelund, U.; Freedson, P.S.; Gary, R.A.; Richardson, C.R.; Smith, D.T.; Swartz, A.M.; American Heart Association Physical Activity Committee of the Council on Lifestyle and Cardiometabolic Health and Cardiovascular, Exercise, Cardiac Rehabilitation and Prevention Committee of the Council on Clinical Cardiology, and Council. Guide to the Assessment of Physical Activity: Clinical and Research Applications A Scientific Statement from the American Heart Association. Circulation 2013. [CrossRef] [PubMed]

33. Stiles, V.H.; Pearce, M.; Moore, I.S.; Langford, J.; Rowlands, A.V. Wrist-worn Accelerometry for Runners: Objective Quantification of Training Load. Med. Sci. Sports Exerc. 2018, 50, 2277. [CrossRef] [PubMed]

34. Arvidsson, D.; Fridolfsson, J.; Börjesson, M.; Andersen, L.B.; Ekblom, Ö.; Dencker, M.; Brønd, J.C. Re-examination of accelerometer data processing and calibration for the assessment of physical activity intensity. Scand. J. Med. Sci. Sports 2019, 29, 1442-1452. [CrossRef] [PubMed]

35. Esliger, D.W.; Rowlands, A.V.; Hurst, T.L.; Catt, M.; Murray, P.; Eston, R.G. Validation of the GENEA Accelerometer. Med. Sci. Sports Exerc. 2011, 43, 1085-1093. [CrossRef]

36. Menai, M.; van Hees, V.T.; Elbaz, A.; Kivimaki, M.; Singh-Manoux, A.; Sabia, S. Accelerometer assessed moderate-to-vigorous physical activity and successful ageing: Results from the Whitehall II study. Sci. Rep. 2017, 8, 45772. [CrossRef]

37. Welch, W.A.; Bassett, D.R.; Thompson, D.L.; Freedson, P.S.; Staudenmayer, J.W.; John, D.; Steeves, J.A.; Conger, S.A.; Ceaser, T.; Howe, C.A.; et al. Classification accuracy of the wrist-worn gravity estimator of normal everyday activity accelerometer. Med. Sci. Sports Exerc. 2013, 45, 2012-2019. [CrossRef]

38. Migueles, J.H.; Cadenas-Sanchez, C.; Tudor-Locke, C.; Löf, M.; Esteban-Cornejo, I.; Molina-Garcia, P.; Mora-Gonzalez, J.; Rodriguez-Ayllon, M.; Garcia-Marmol, E.; Ekelund, U.; et al. Comparability of published cut-points for the assessment of physical activity: Implications for data harmonization. Scand. J. Med. Sci. Sports 2019, 29, 566-574. [CrossRef]

39. Hernando, C.; Hernando, C.; Collado, E.J.; Panizo, N.; Martinez-Navarro, I.; Hernando, B. Establishing cut-points for physical activity classification using triaxial accelerometer in middle-aged recreational marathoners. PLoS ONE 2018, 13, e0202815. [CrossRef]

40. Hernando, C.; Hernando, C.; Martinez-Navarro, I.; Collado-Boira, E.; Panizo, N.; Hernando, B. Estimation of energy consumed by middle-aged recreational marathoners during a marathon using accelerometry-based devices. Sci. Rep. 2020, 10, 1523. [CrossRef]

41. Bernat-Adell, M.D.; Collado-Boira, E.J.; Moles-Julio, P.; Panizo-González, N.; Martínez-Navarro, I.; Hernando-Fuster, B.; Hernando-Domingo, C. Recovery of Inflammation, Cardiac, and Muscle Damage Biomarkers After Running a Marathon. J. Strength Cond. Res. 2019. [CrossRef]

42. Abe, D.; Fukuoka, Y.; Horiuchi, M. Economical Speed and Energetically Optimal Transition Speed Evaluated by Gross and Net Oxygen Cost of Transport at Different Gradients. PLoS ONE 2015, 10, e0138154. [CrossRef] [PubMed]

43. Byrne, N.M.; Hills, A.P.; Hunter, G.R.; Weinsier, R.L.; Schutz, Y. Metabolic equivalent: One size does not fit all. J. Appl. Physiol. (Bethesda Md. 1985) 2005, 99, 1112-1119. [CrossRef] [PubMed]

44. Lazzer, S.; Taboga, P.; Salvadego, D.; Rejc, E.; Simunic, B.; Narici, M.V.; Buglione, A.; Giovanelli, N.; Antonutto, G.; Grassi, B.; et al. Factors affecting metabolic cost of transport during a multi-stage running race. J. Exp. Biol. 2014, 217, 787-795. [CrossRef] [PubMed]

45. Skinner, J.S.; McLellan, T.M.; McLellan, T.H. The transition from aerobic to anaerobic metabolism. Res. Q. Exerc. Sport 1980, 51, 234-248. [CrossRef] [PubMed] 
46. Betts, J.A.; Smith, H.A.; Johnson-Bonson, D.A.; Ellis, T.I.; Dagnall, J.; Hengist, A.; Carroll, H.; Thompson, D.; Gonzalez, J.T.; Afman, G.H. The Energy Cost of Sitting versus Standing Naturally in Man. Med. Sci. Sports Exerc. 2018. [CrossRef] [PubMed]

47. Lazzer, S.; Salvadego, D.; Rejc, E.; Buglione, A.; Antonutto, G.; di Prampero, P.E. The energetics of ultra-endurance running. Eur. J. Appl. Physiol. 2012, 112, 1709-1715. [CrossRef]

48. Nikolaidis, P.T.; Ćuk, I.; Knechtle, B. Pacing of Women and Men in Half-Marathon and Marathon Races. Medicina (Kaunas Lith.) 2019, 55, 14. [CrossRef]

49. de Blas, X.; Padullés, J.M.; López del Amo, J.L.; Guerra-Balic, M. Creation and Validation of ChronojumpBoscosystem: A Free Tool to Measure Vertical Jumps. Int. J. Sport Sci. 2012, 8, 334-356. [CrossRef]

50. Fritz, C.O.; Morris, P.E.; Richler, J.J. Effect size estimates: Current use, calculations, and interpretation. J. Exp. Psychol. Gen. 2012, 141, 2-18. [CrossRef]

51. Lenhard, W.; Lenhard, A. Calculation of Effect Sizes. Psychometrica 2016. [CrossRef]

52. Thomas, J.R.; Nelson, J.K.; Silverman, S.J. Research Methods in Physical Activity; Human Kinetics: Champaign, IL, USA, 2015; ISBN 978-1-4925-8528-2.

53. Nikolaidis, P.T.; Rosemann, T.; Knechtle, B. Force-Velocity Characteristics, Muscle Strength, and Flexibility in Female Recreational Marathon Runners. Front. Physiol. 2018, 9, 1563. [CrossRef] [PubMed]

54. Deaner, R.O.; Carter, R.E.; Joyner, M.J.; Hunter, S.K. Men are more likely than women to slow in the marathon. Med. Sci. Sports Exerc. 2015, 47, 607-616. [CrossRef] [PubMed]

55. Knechtle, B.; Nikolaidis, P.T. Physiology and Pathophysiology in Ultra-Marathon Running. Front. Physiol. 2018, 9, 634. [CrossRef]

56. Eichenberger, E.; Knechtle, B.; Knechtle, P.; Rüst, C.A.; Rosemann, T.; Lepers, R. Best performances by men and women open-water swimmers during the "English Channel Swim" from 1900 to 2010. J. Sports Sci. 2012, 30, 1295-1301. [CrossRef]

57. Senefeld, J.; Joyner, M.J.; Stevens, A.; Hunter, S.K. Sex differences in elite swimming with advanced age are less than marathon running. Scand. J. Med. Sci. Sports 2016, 26, 17-28. [CrossRef]

58. Frick, B. Gender Differences in Competitive Orientations: Empirical Evidence from Ultramarathon Running. J. Sports Econ. 2011, 12, 317-340. [CrossRef]

59. Tarnopolsky, L.J.; MacDougall, J.D.; Atkinson, S.A.; Tarnopolsky, M.A.; Sutton, J.R. Gender differences in substrate for endurance exercise. J. Appl. Physiol. (Bethesda Md. 1985) 1990, 68, 302-308. [CrossRef] [PubMed]

60. Tarnopolsky, M.A. Sex differences in exercise metabolism and the role of 17-beta estradiol. Med. Sci. Sports Exerc. 2008, 40, 648-654. [CrossRef] [PubMed]

61. Temesi, J.; Arnal, P.J.; Rupp, T.; Féasson, L.; Cartier, R.; Gergelé, L.; Verges, S.; Martin, V.; Millet, G.Y. Are Females More Resistant to Extreme Neuromuscular Fatigue? Med. Sci. Sports Exerc. 2015, 47, 1372-1382. [CrossRef] [PubMed]

(C) 2020 by the authors. Licensee MDPI, Basel, Switzerland. This article is an open access article distributed under the terms and conditions of the Creative Commons Attribution (CC BY) license (http://creativecommons.org/licenses/by/4.0/). 